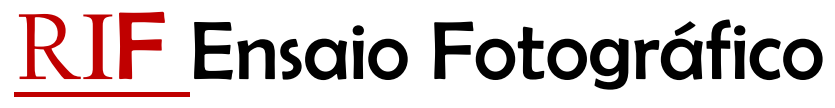

DOI - 10.5212/RIF.v.17.i39.0014

\section{Ensaio fotoetnográfico na aldeia Sateré-Mawé (AM) de Ponta Alegre, na Amazônia central}

Fotos e texto: Gleilson Medins ${ }^{1}$

Este ensaio fotográfico foi produzido em 2014 na ocasião da gravação do vídeo documentário Memorial Sateré-Mawé: Ponta Alegre, nossa aldeia, editado pelo Núcleo de Antropologia Urbana da USP/NAU, em parceria com o Instituto de Ciências Sociais, Educação e Zootecnia (ICSEZ-UFAM). Ponta Alegre é a maior aldeia indígena (ou comunidade de indígenas não aldeados, como eles preferem) Sateré no Rio Andirá/AM, e está à margem de muitos mundos.

Trata-se de uma abordagem folkcomunicacional do olhar fotográfico, quando da observação participante por um período de 15 dias de vivência etnográfica com indígenas da etnia Sateré-Mawé, no município de Barreirinha/AM. A ideia foi captar urbanidades presentes na comunidade (eles não chamam de aldeia).

A tradição oral é latente em sua cultura. A língua materna é falada por todos os velhos e repassada a jovens, até mesmo dentro da escola da comunidade. Apesar dos contornos de urbanização e da iminente hibridização cultural, vestuário, artesanato, técnicas de caça e pesca e etnoconhecimento para curar males por meio de ervas e benzeduras e para a construção de casas caminham lado a lado com a apropriação das novas tecnologias.

A objetiva da câmera buscou captar estas pistas deste grupo social relativamente marginalizado, sociocultural e midiaticamente. É em Ponta Alegra que se encontram memórias de transformações e aprendizados dos contatos de seus moradores com os não indígenas ao longo do tempo. Este ensaio fotoetnográfico percorre travessias de mundos e revela parte do modo de vida da aldeia, onde memórias do passado resistem e convivem com transformações do presente, (re)definindo um futuro para os Sateré de Barreirinha.

\footnotetext{
${ }^{1}$ Mestre em Sociedade e Cultura na Amazônia pela Universidade Federal do Amazonas e bacharel em Comunicação Social/Jornalismo pela mesma instituição. Coordenador Administrativo e Técnico Audiovisual da Faculdade de Informação e Comunicação da Universidade Federal do Amazonas (FIC/UFAM). E-mail: gleilsonmedins@ufam.edu.br.
} 
RIF, Ponta Grossa/ PR Volume 17, Número 39, p.226-238, Julho/Dezembro 2019

Foto 01: Ajuda nativa para a gravação

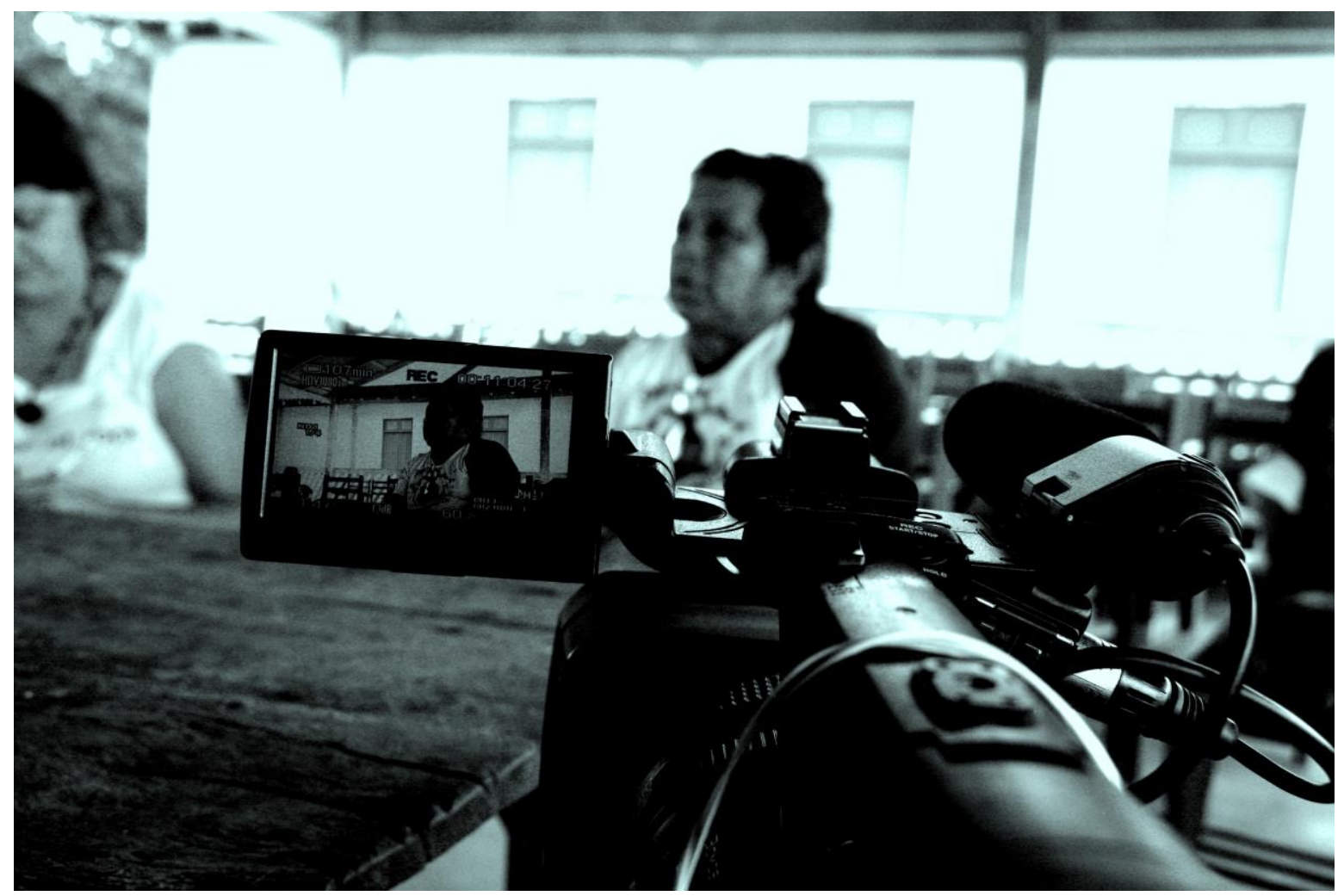


RIF, Ponta Grossa/ PR Volume 17, Número 39, p.226-238, Julho/Dezembro 2019

Foto 02: À beira do rio Amazonas: Pôr do sol em Ponta Alegre

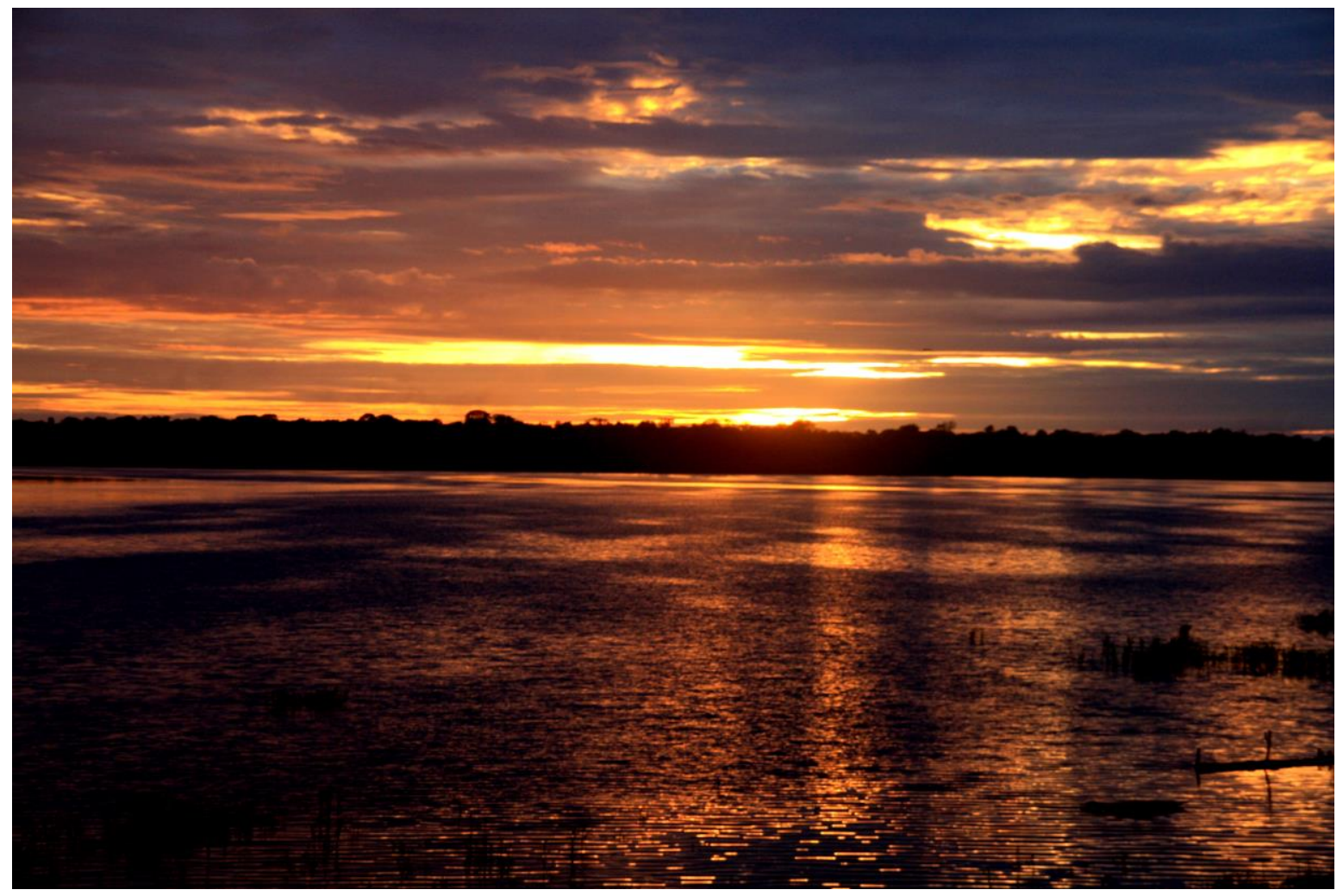


RIF, Ponta Grossa/ PR Volume 17, Número 39, p.226-238, Julho/Dezembro 2019

Foto 03: Sobre faces originárias

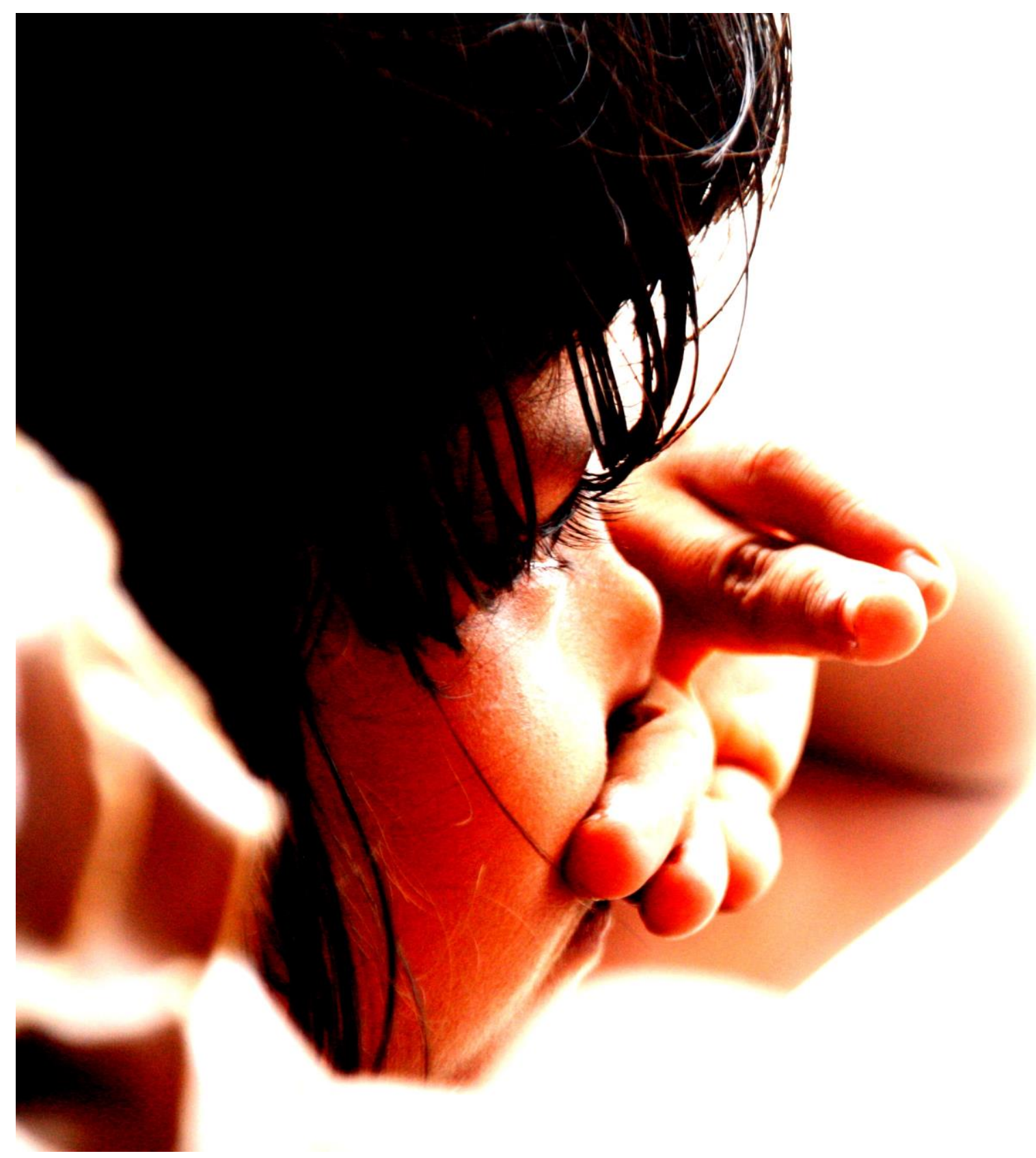


RIF, Ponta Grossa/ PR Volume 17, Número 39, p.226-238, Julho/Dezembro 2019

Foto 04: Reunião na Maloca: Alegria de curumins e cunhantãs

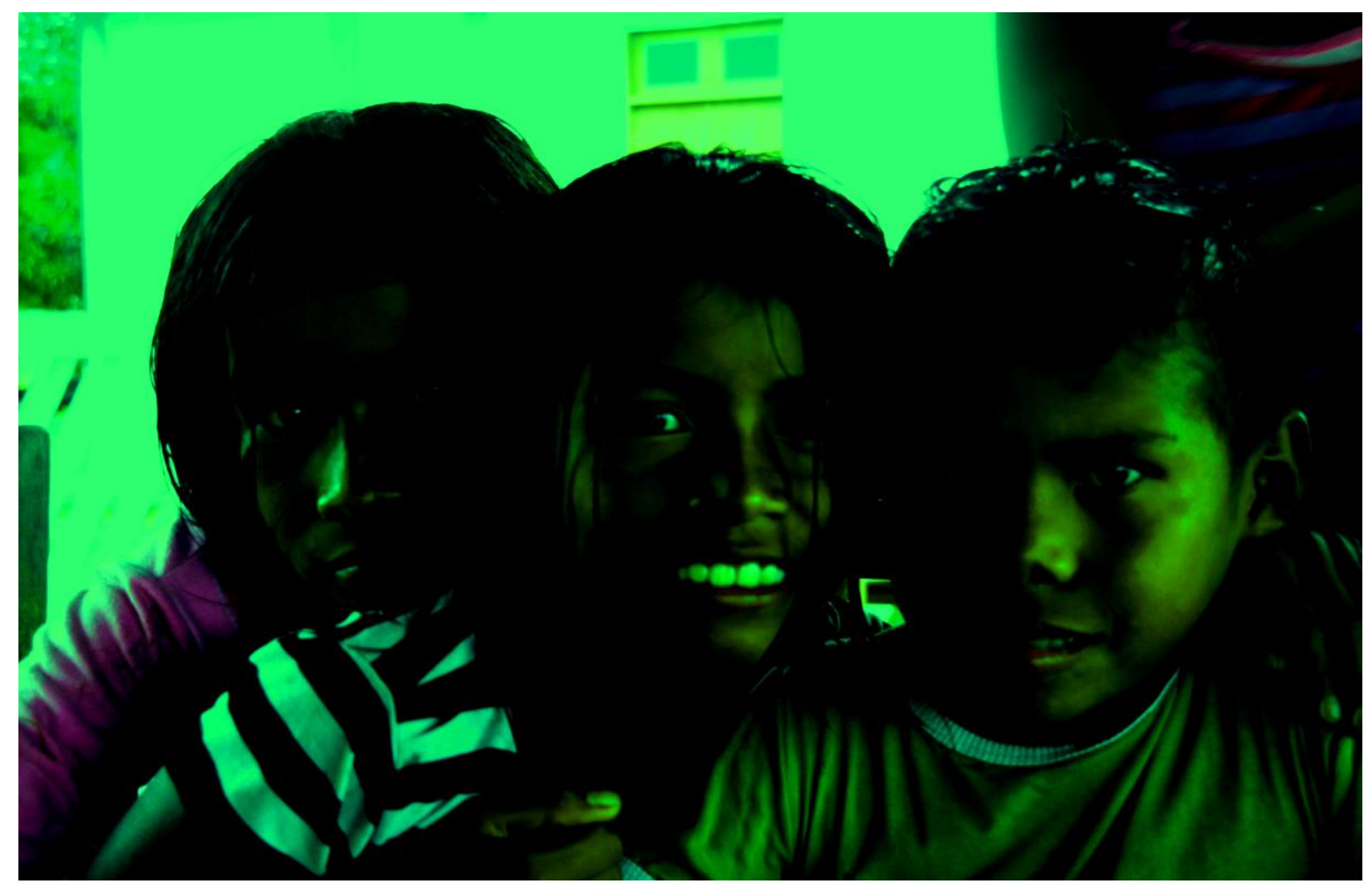


RIF, Ponta Grossa/ PR Volume 17, Número 39, p.226-238, Julho/Dezembro 2019

Foto 05: Ponta Alegre: Uma comunidade autônoma

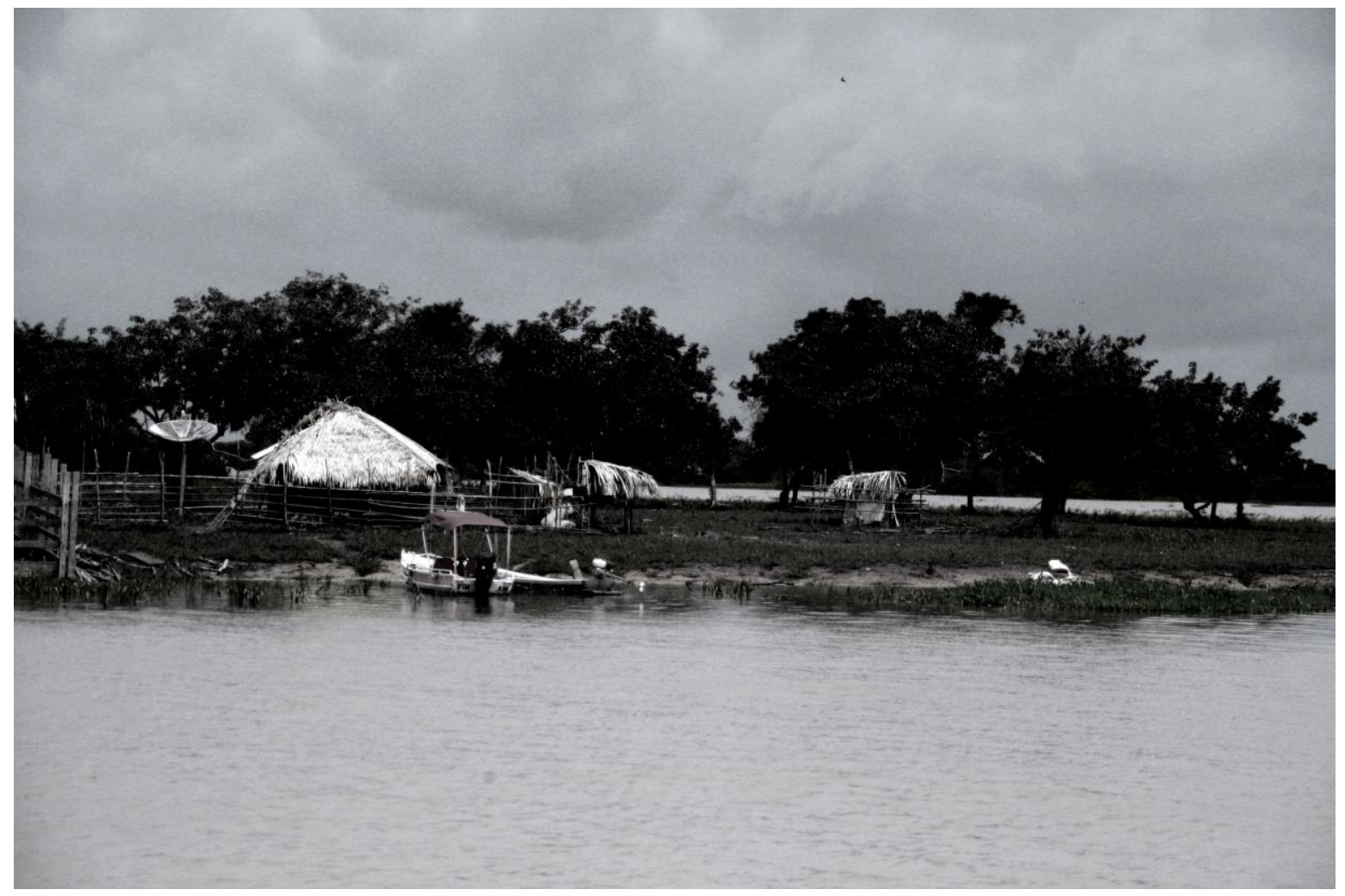


RIF, Ponta Grossa/ PR Volume 17, Número 39, p.226-238, Julho/Dezembro 2019

Foto 06: No cotidiano dos Sataré

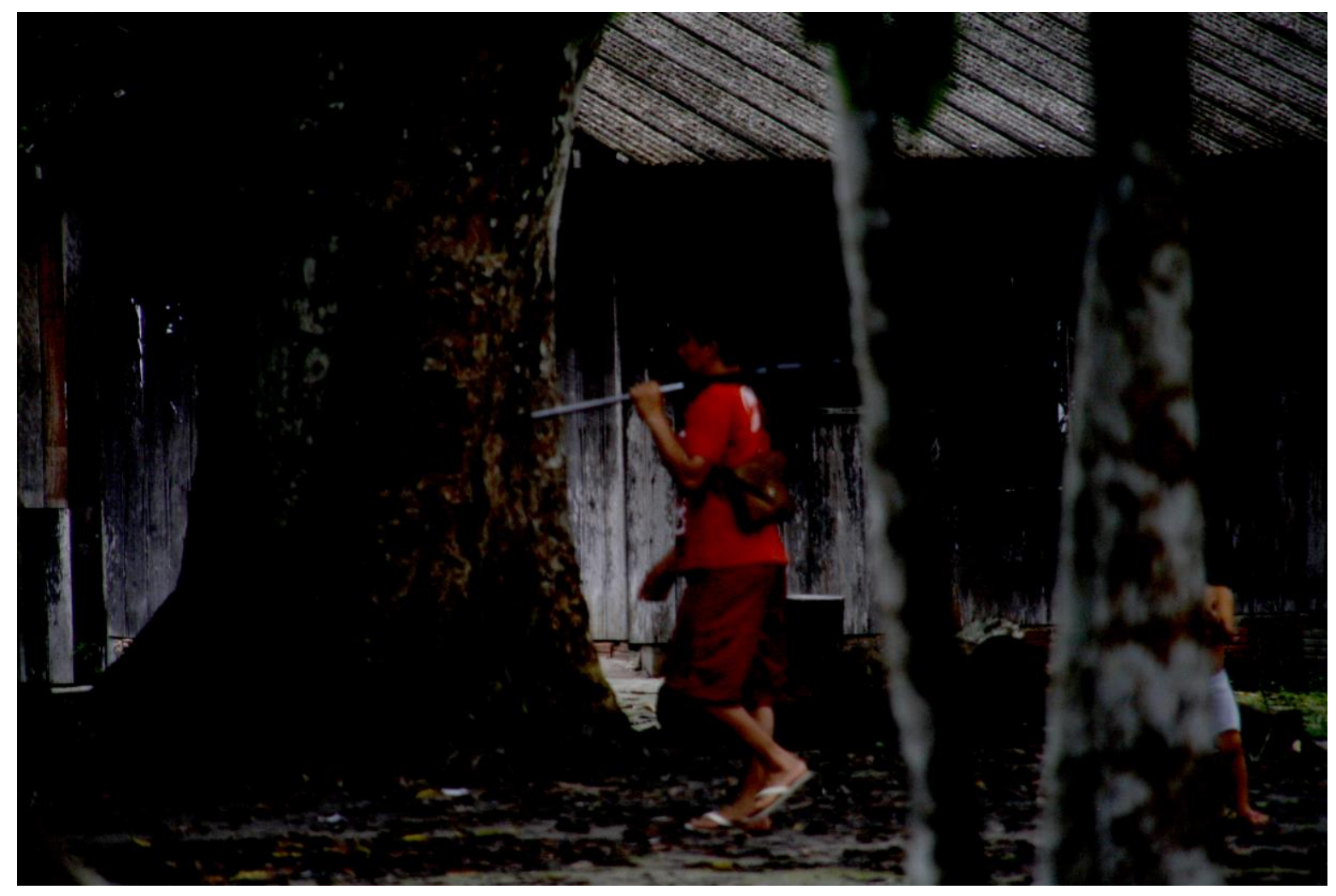


RIF, Ponta Grossa/ PR Volume 17, Número 39, p.226-238, Julho/Dezembro 2019

Foto 07: Nas cercanias da terra indígena Andirá-Marau

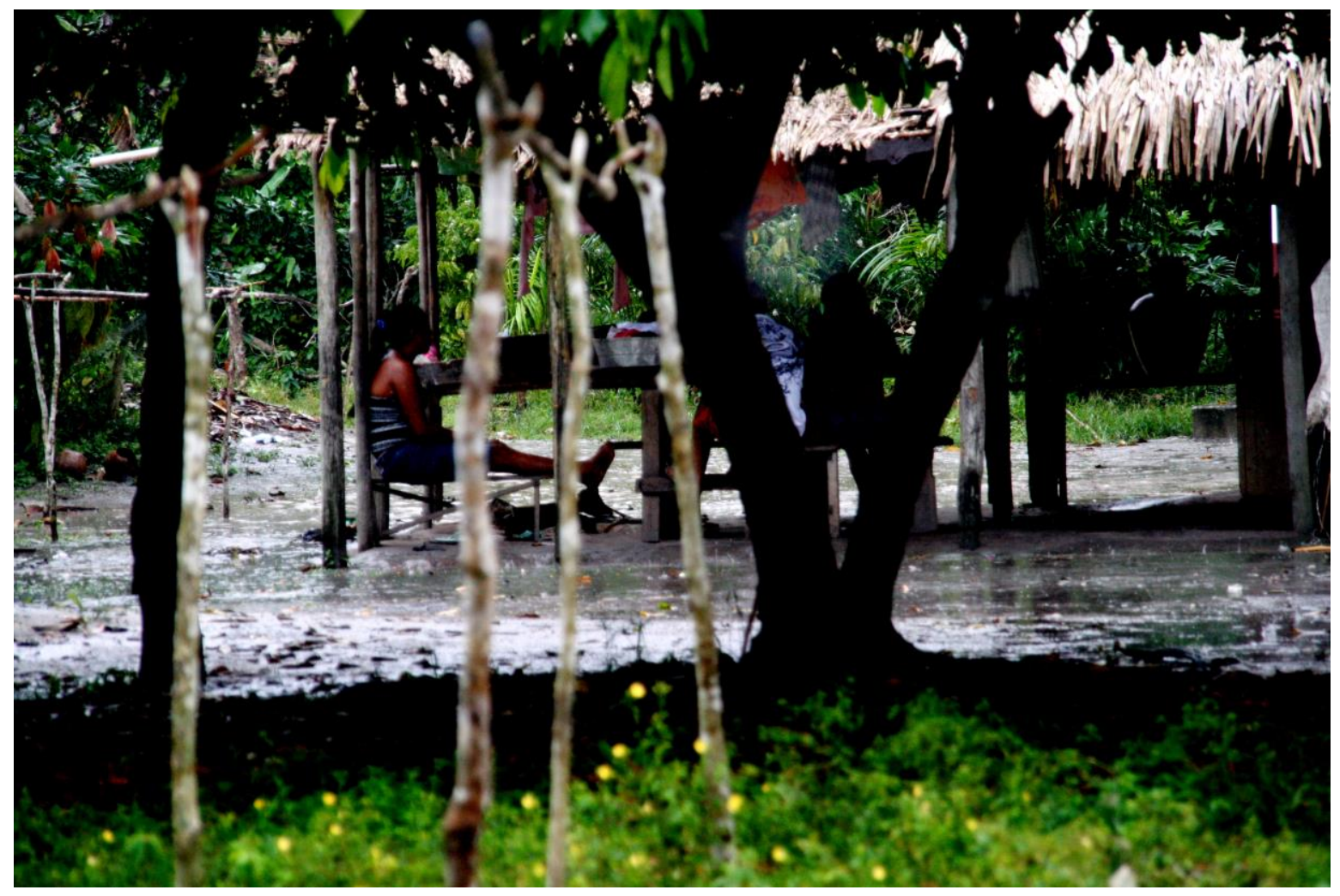


RIF, Ponta Grossa/ PR Volume 17, Número 39, p.226-238, Julho/Dezembro 2019

Foto 08: Imersão da equipe do NAU-USP e do ICSEZ-UFM em campo

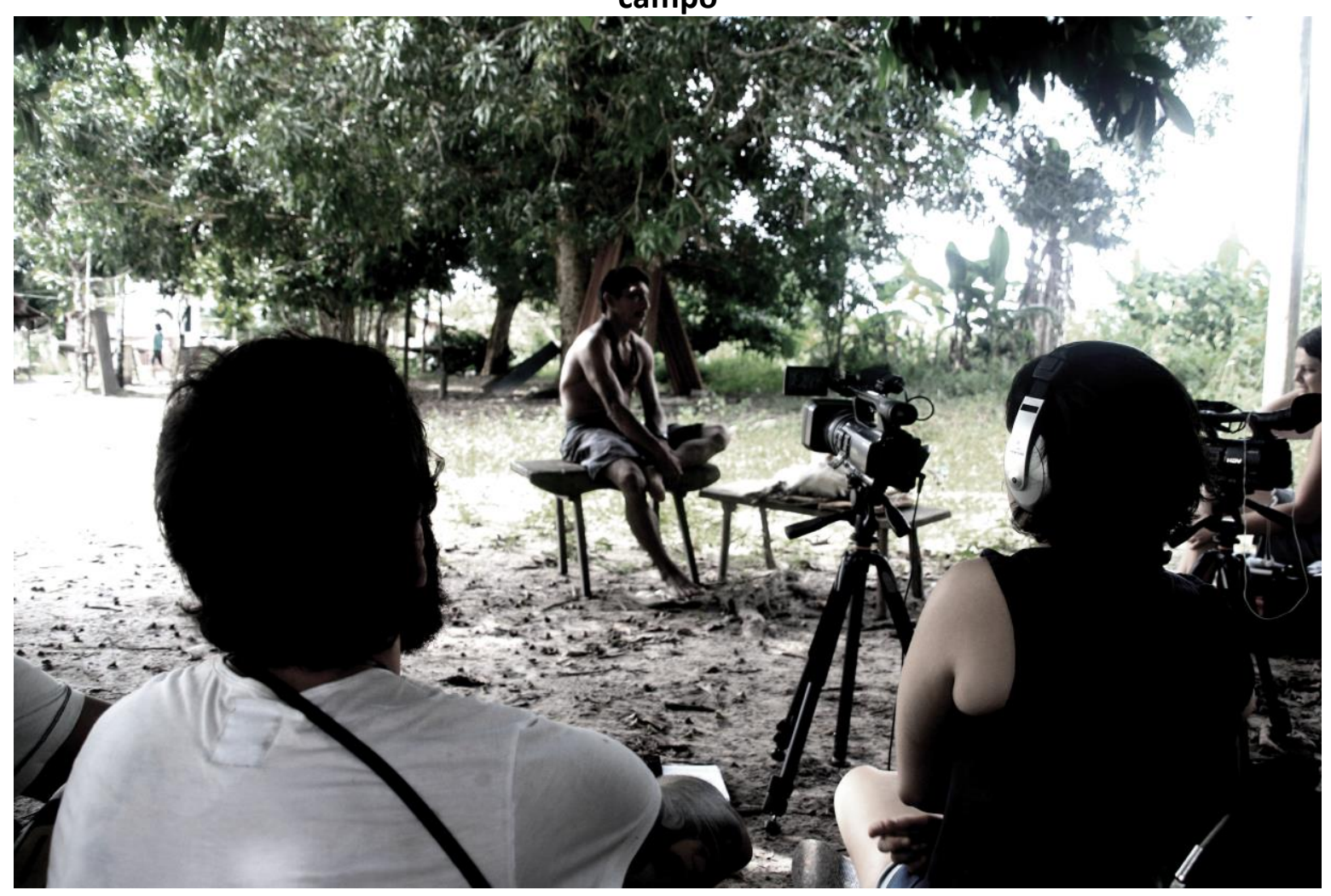


RIF, Ponta Grossa/ PR Volume 17, Número 39, p.226-238, Julho/Dezembro 2019

Foto 09: Diálogo em construção: Confluindo culturas e entendimentos

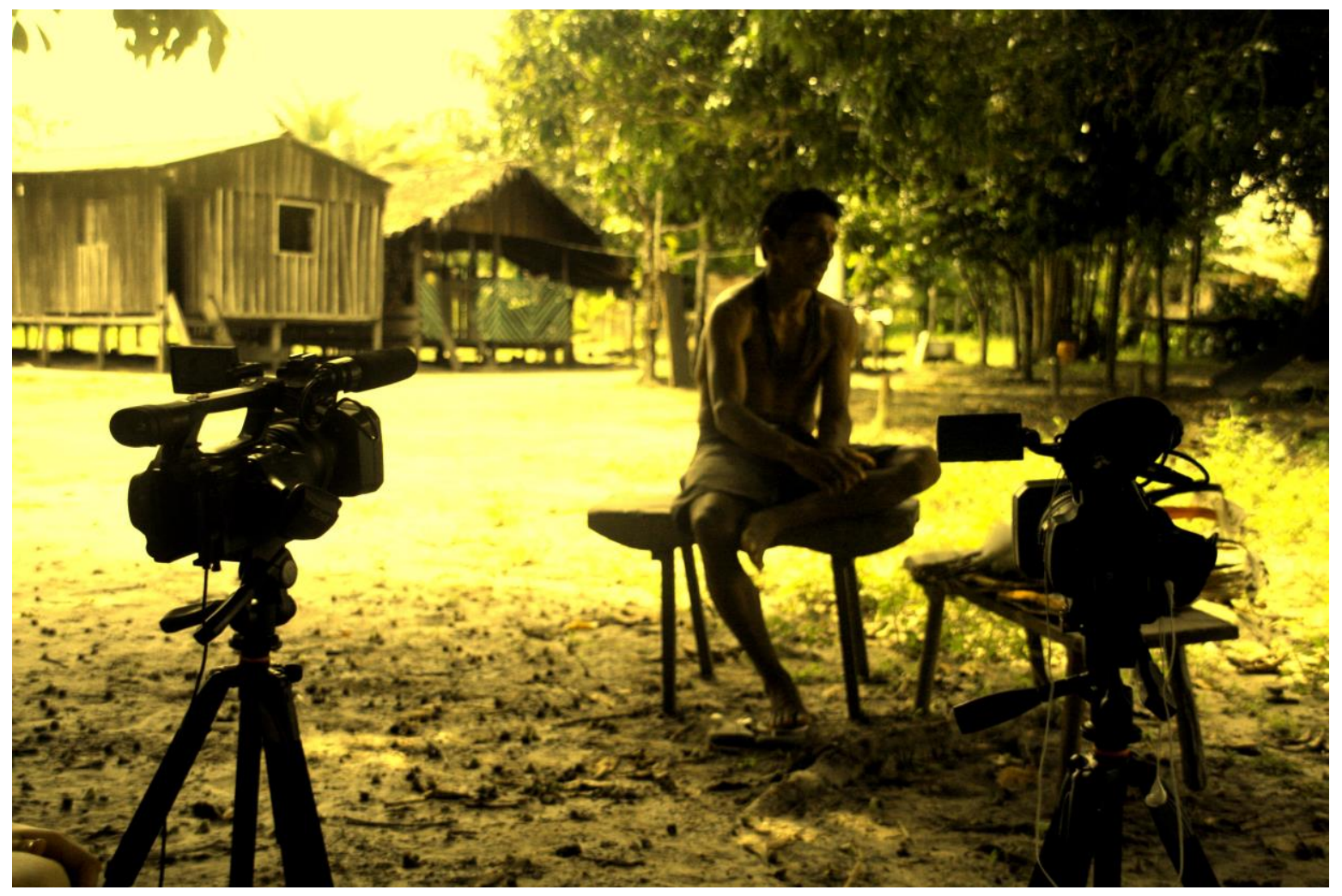


RIF, Ponta Grossa/ PR Volume 17, Número 39, p.226-238, Julho/Dezembro 2019

Foto 10: Dia de caçada e a curiosidade do estranho

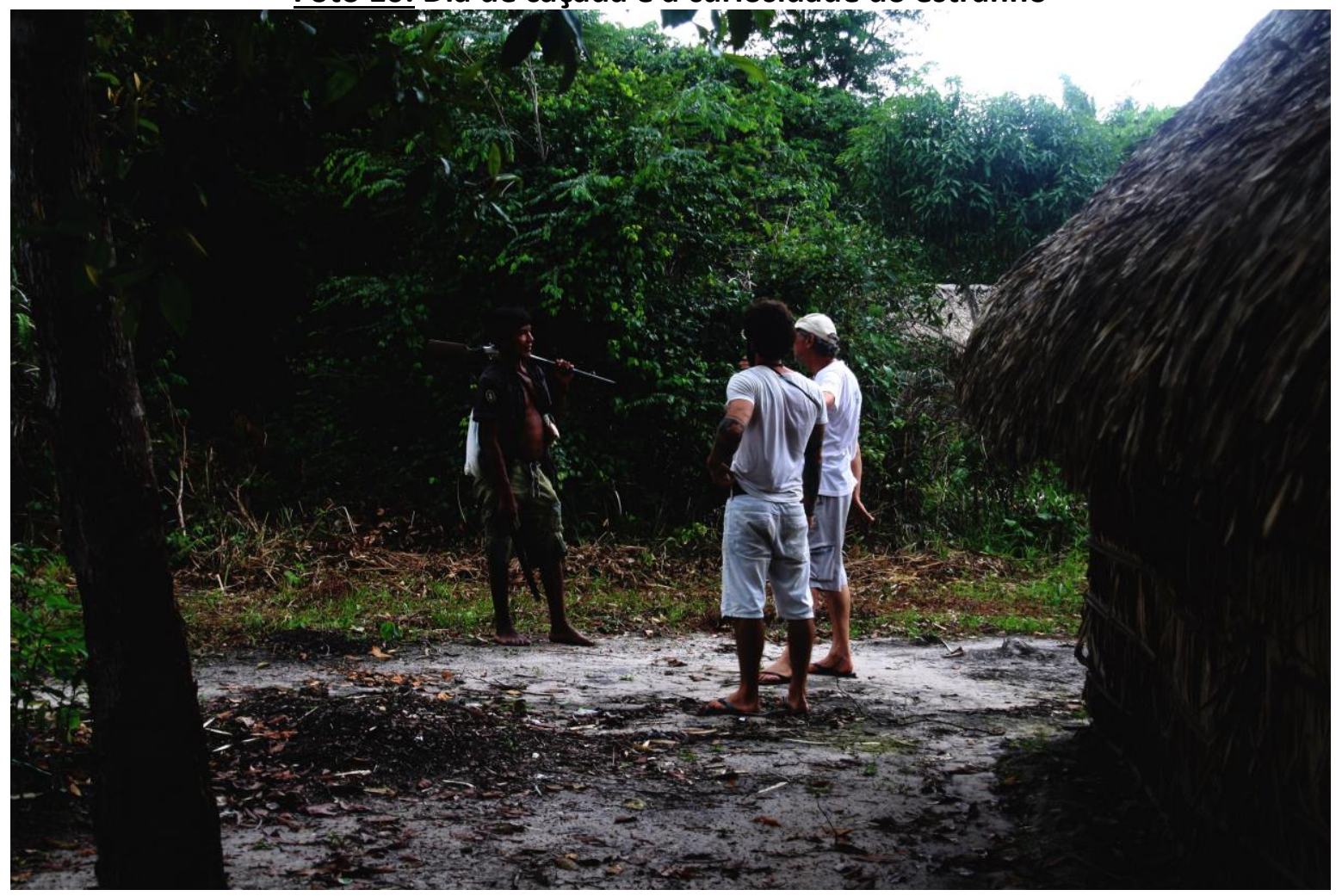


RIF, Ponta Grossa/ PR Volume 17, Número 39, p.226-238, Julho/Dezembro 2019

Foto 11: Cunhatã em foco

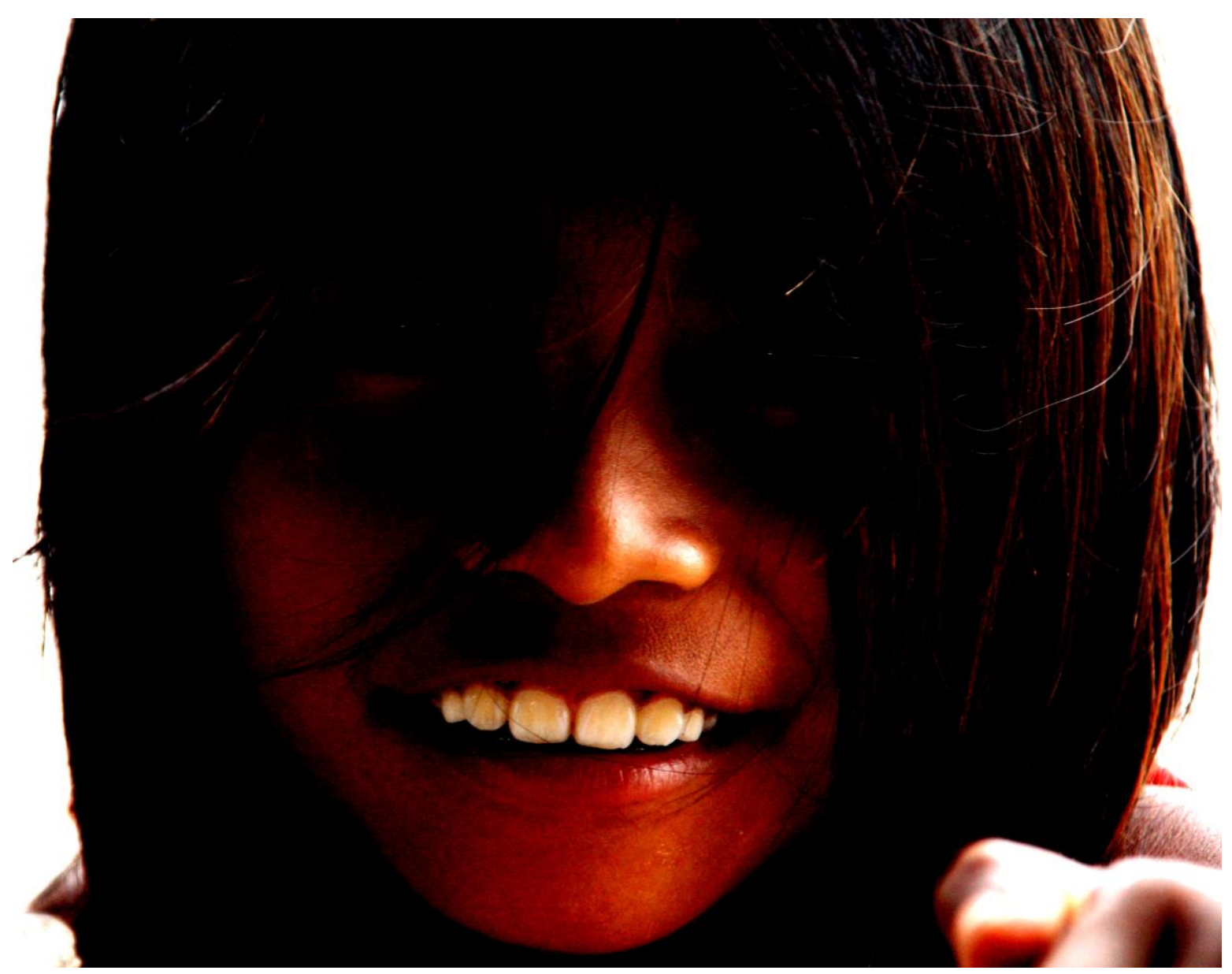


RIF, Ponta Grossa/ PR Volume 17, Número 39, p.226-238, Julho/Dezembro 2019

Foto 12: Brincadeira de criança: Contemplando a chuva

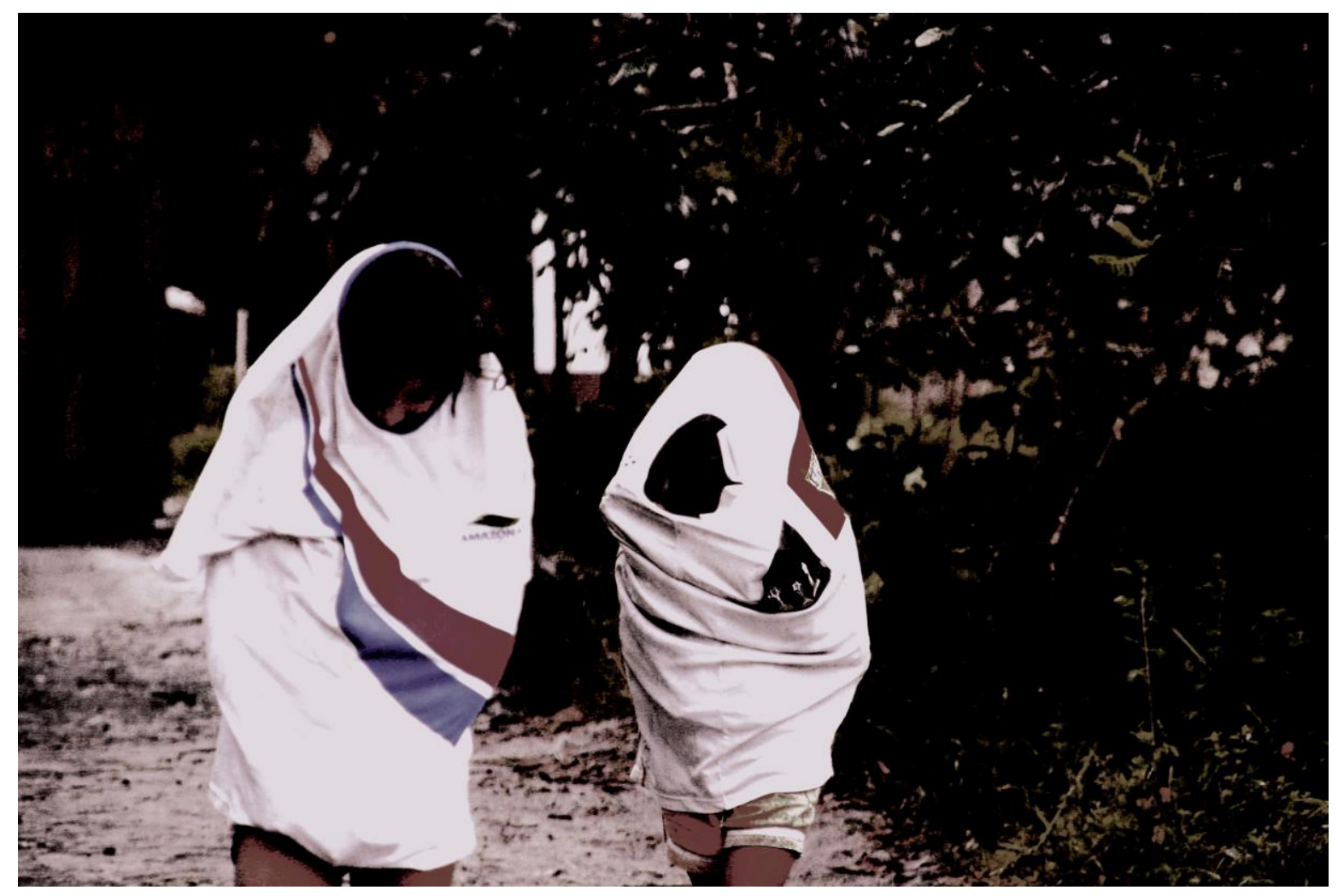

